\title{
2. New outlooks with tianeptine in the treatment of mood disturbances
}

\section{NEUROCHEMICAL, NEUROENDOCRINE AND BEHA VIOURAL EFFECTS OF TIANEPTINE IN ANIMALS AND THEIR CLINICAL RELEVANCE}

G Curzon. K.P.Datla

Department of Neurochemistry, Institute of Neurology, 1 Wakefield Street, London, WC1N 1PJ, England

There is strong evidence that the therapeutic action of many antidepressants is mediated by increased availability of 5-HT to receptors. It is therefore remarkable that the tricyclic antidepressant tianeptine has an opposite effect. Thus, ex vivo it enhances 5-HT uptake by platelets and synaptosome, while in vivo we find that it inhibits the increase of dialysate (i.e. extracellular) 5-HT in the rat hippocampus caused by $\mathrm{K}^{+}$stimulation and decreases both the rise of extracellular 5-HT in the frontal cortex elicited by the 5-HT precursor 5-HTP and the associated behavioural response (wet-dog shakes). It is difficult to explain the antidepressant properties of tianeptine in terms of these findings. One possibility is that its effect on 5-HT is responsible for its reported ability to attenuate the activation of the HPA axis by stress and that this is involved in the antidepressant action. Another is that other effect of the drug may be important e.g. its property of increasing extracellular dopamine in limbic regions which could have hedonic consequences.

Various reported effects of tianeptine in animal experiments are highly consistent with its ability to decrease the availability of 5-HT to receptors e.g. anxiolysis and enhancement of locomotion, wakefulness, attentiveness and memory. It may be however that effects of the drug on other transmitter systems are also involved in the latter response e.g. activation of either glutamatergic $\mathrm{CA}_{1}$ pyramidal cells or of cholinergic mechanisms.
EFFECT OF TIANEPTINE ON STRESS-INDUCED EFFECTS IN RATS

\section{Bruce S. McEwen}

Laboratory of Neuroendocrinology, Rockefeller University, 1230 York Avenue, New York, N.Y. 10021.

Repeated restraint stress in rats for 3 wks causes changes in the hippocampal formation that include reduction of $5-\mathrm{HT}_{1 \mathrm{~A}}$ receptor binding and atrophy of dendrites of $\mathrm{CA}_{3}$ pyramidal neurons. Three weeks of $6 \mathrm{~h} / \mathrm{d}$ restraint stress causes not only dendritic atrophy but also impaiment of initial learning in a radial arm maze. Tianeptine treatment $(10 \mathrm{mg} / \mathrm{kg} / \mathrm{d})$ prevented the stress-induced atrophy of dendrites of $\mathrm{CA}_{3}$ pyramidal neurons, whereas desipramine $(10 \mathrm{mg} / \mathrm{kg} / \mathrm{d})$ and fluoxetine $(10 \mathrm{mg} / \mathrm{kg} / \mathrm{d})$ did not do so. Tianeptine treatment also prevented the stress-induced impairment of radial maze learning. However tianeptine treatment did not alter the stress-induced reduction of hippocampal 5-HTA $1 \mathrm{~A}$ receptor binding, nor did it produce major shifts in $5-\mathrm{HT}_{1 \mathrm{~A}}, 5-\mathrm{HT}_{1 \mathrm{~B}}$ or $5-\mathrm{HT} 2$ receptor binding. $\left[{ }^{3} \mathrm{H}\right]$ paroxetine binding to the serotonin transporter was slightly reduced by tianeptine treatment. Exogenous corticosterone treatment also produced atrophy of dendrites of $\mathrm{CA}_{3}$ pyramidal neurons, and this effect was also blocked by tianeptine $(15 \mathrm{mg} / \mathrm{kg} /$ day) treatment. Thus the effect of tianeptine on $\mathrm{CA}_{3}$ morphology is not due to its reported effects to reduce corticosterone secretion but may instead be related to its reported effects to enhance the reuptake of serotonin. Because corticosterone and stress-induced atrophy of $\mathrm{CA}_{3}$ dendrites is also blocked by phenytoin, an inhibitor of excitatory amino acid release and actions, these results suggest that serotonin released by stress or corticosterone may interact pre- or post-synaptically with glutamate released by stress or corticosterone, and that the final common path may involve interactive effects between serotonin and glutamate receptors on the dendrites of $\mathrm{CA}_{3}$ neurons and that mossy fiber input from the dentate gyrus may play a key role. 
EFFECTS OF TIANEPTINE ON BENZODIAZEPINE AND ALCOHOL WITHDRAWAL

Sandra E. File, Nick Andrews

Psychopharmacology Research Unit, UMDS Division of Pharmacology, Guy's Hospital, London SE1 9RT.

Rats were treated with diazepam ( $2 \mathrm{mg} / \mathrm{kg} /$ day) for 21 days, or ethanol added to liquid diet in concentrations increasing over 2 weeks and then maintained for a further 4 weeks at a mean intake of $11.6 \mathrm{~g} / \mathrm{kg} / \mathrm{day}$. Control rats received daily distilled water injections or the liquid diet without ethanol. Pairs of rats were tested in the low light, familiar condition of the social interaction test of anxiety, $24 \mathrm{~h}$ after the last chronic injection or $12 \mathrm{~h}$ after removal of the liquid diet. Control-treated, diazepam and ethanol withdrawn rats were randomly allocated to vehicle or tianeptine $(2.5,5$ or $10 \mathrm{mg} / \mathrm{kg}$ i.p.) injection on test day, and this was given $\mathbf{3 0}$ min prior to behavioural testing. Tianeptine (5 and $10 \mathrm{mg} / \mathrm{kg}$ ) significantly reversed the anxiogenic response on withdrawal from diazepam and these reversals were independent of any changes in motor activity. Tianeptine $(2.5$ and $10 \mathrm{mg} / \mathrm{kg}$ ) also significantly reversed the anxiogenic response and the hypoactivity that occurred on withdrawal from ethanol. It has been hypothesised that the increased anxiety on withdrawal from benzodiazepines and ethanol is due to an increase in 5-HT release in limbic areas. The reversals by tianeptine of this withdrawal anxiety are therefore likely to result from its action to increase 5-HT uptake.

\section{TIANEPTINE AND ANXIETY}

S. RUSCHEL*, LA, COSTA E SILVA, S.ARRUDA, D. CAETANO G. CUCCHIARO, T, DE CARVALHO, R. LIPPI, J. PAPROCKI, F. ROCHA,

*Hospital Santa Casa da Misericordia - Rio de Janeiro, Brazil

In spite of its neurochemical action (increase in serotonin uptake at the presynaptic level), the antidepressant tianeptine shows an anxiolytic profile in pharmacological studies identical to that of new serotoninergic agents $(1)$. It is inactive in the standard screening tests for benzodiazepine anxiolytics, however it antagonizes the anxiogenic effect of benzodiazepine withdrawal $(2)$. In clinical studies, tianeptine has been shown to be as effective as amitriptyline in the treatment of anxiety linked to depression in patients fulfilling DSMIIIR criteria for depression and FDA criteria for anxiety ${ }^{(3)}$, in patients with depression induced by alcohol withdrawal ${ }^{(4)}$. In a recent placebo controlled study, tianeptine has been shown to be more active on anxiety linked to depression than placebo(5). A specific study aiming to assess the efficacy of tianeptine in patients with Generalized Anxiety Disorder without depression was performed. In this placebo controlled study, the 88 patients had a minimum HARS score of 20 . They were treated by either tianeptine $(37.5 \mathrm{mg} /$ day $)$ or placebo for 42 days. Efficacy was evaluated using HARS scale, Covi scale, CGi scale, Zung anxiety scale and a VAS. This study will provide results about the specific anti-anxiety activity of tianeptine in anxious patients.

(1)File S.E., Mabutt P.S. - Drug Develop. Res. 1991, 23, 47-56.

(2) File S.E., Andrews N., Zangrossi H., - Eur. Psychiatry, 1993, 8, suppl. 2, 75S-80S.

(3) Guelfi J.D., Pichot P., Dreyfus J.F., - Neuropsychobiology, 1989, 22, $41-48$.

(4) Lôo H., Malka R. et al - Neuropsychobiology, 1988, 19, 79-85.

(5) Staner L. et al, - 7th Congress of Association of European Psychiatrists - 18-22 September 1994.
DIAGNOSIS AND TREATMENT OF ADJUSTMENT DISORDERS AND MIXED ANXIETY-DEPRESSIVE DISORDERS MAnsseau

Psychiatric Unit, C.H.U. du Sart Tilman, B-4000 Liege, Belgium

The essential feature of adjustment disorder is a maladaptive reaction to an identifiable psychosocial stressor, or stressors, that occurs within 3 months after onset of the stressor, and has persisted for no longer than 6 months. The maladaptive nature of the reaction is indicated either by impainnent of occupational functioning or in usual social activities or relationships with others or by symptoms that are in excess of a normal and expectable reaction to the stressor. Among the various types, adjustment disorder with mixed emotional features (anxiety and depression) could be one of the most common, particularly seen by general practitioners. Moreover, the frequent coexistence of depressive and anxiety symptoms led to the inclusion of mixed anxiety-depressive disorder in ICD-10 (F 41.2) and in the proposals for new categories in DSM-IV. A recent international study showed that $43.7 \%$ of patients with current depressive episode presenting in primary care settings were considered as mixed anxiety-depressive disorders by general practitioners (Sartorius et al., Arch. Gen. Psychiatry, 50, 819, 1993). The pharmacological treatment of such conditions is far from established : in the international project, $23.7 \%$ of patients received anxiolytics and $27.8 \%$ antidepressants. The importance of such categories both at the diagnostic and treatment levels will be stressed, taken as an example a recent study comparing the efficacy of tianeptine, mianserine, and alprazolam in 134 patients with adjustment disorder with mixed emotional features. 